American Journal of Applied Sciences 6 (6): 1180-1185, 2009

ISSN 1546-9239

(C) 2009 Science Publications

\title{
Determination of the Presence of Huanglongbing in Seeds and Movement of the Pathogen in Citrus reticulata
}

\author{
${ }^{1}$ Hajivand Shokrollah, ${ }^{1}$ Thohirah Lee Abdullah, \\ ${ }^{2}$ Kamaruzaman Sijam and ${ }^{3}$ Siti Nor Akmar Abdullah \\ ${ }^{1}$ Departments of Crop Science, Faculty of Agriculture, \\ University Putra Malaysia, 43400 Serdang, Selangor Darul Ehsan \\ ${ }^{2}$ Department of Plant Protection, Faculty of Agriculture, \\ University Putra Malaysia, 43400 Serdang, Selangor Darul Ehsan \\ ${ }^{3}$ Department of Agro Biotechnology, Faculty of Agriculture, \\ University Putra Malaysia, 43400 Serdang, Selangor Darul Ehsan, Malaysia
}

\begin{abstract}
Problem statement: Huanglongbing (HLB) also known as citrus greening disease is a fastidious phloem-inhabiting bacterium in the genus Candidatus Liberibacter. Using universal primers, the $16 \mathrm{~S}$ ribosomal DNA sequence of three strains of the bacterium were obtained by PCR. However there is very little information on seed transmission and HLB pathogen movement to find a way for control or reduce the severity of HLB on the field. The study was conducted to detect HLB pathogen in seeds of Citrus, to determine pathogen movement in citrus seedling after infection and to detect the HLB pathogen in citrus roots. Approach: Seeds of Citrus reticulata cv. Limau Madu were collected from infected orchard and were germinated in screenhouse condition. The seeds of Citrus reticlata cv. L. Madu were planted in screenhouse too for HLB pathogen movement and HLB detection in roots. The seedlings were inoculated using infected grafting methods. Results: HLB was not amplified in new seedlings after germination. HLB moved slowly reaching up to $1.5 \mathrm{~cm}$ after 2 weeks, $1.5-4.5 \mathrm{~cm}$ after eight weeks and detected on 4.5-9 cm after 14 weeks below the grafting area. HLB was also detected up to $9-15 \mathrm{~cm}$ after 16 weeks, $15-24 \mathrm{~cm}$ after twenty weeks, $24-28.5 \mathrm{~cm}$ after 22 weeks and 28.5-30 cm after 24 weeks below the grafting area. Conclusion: Base on conventional PCR test, HLB disease in citrus is not seed borne and it can reach to the roots 26 weeks after inoculation.
\end{abstract}

Key words: HLB, seed borne, pathogen movement, greening disease, citrus

\section{INTRODUCTION}

HLB is caused by a phloem limited pathogen which causes greening disease. HLB is one of the serious diseases of citrus and infected more than 40 countries in the world. The greening pathogen belongs to genus Candidatus Liberibacter. HLB bacteria have not been cultured in media. The isolate from South Africa has been named Candidatus Liberibacter africanus and the isolate from Asia has been named Candidatus Liberibacter asiaticus ${ }^{[1,2]}$. Large areas of citrus orchards had to be eradicated due to HLB disease in citrus industry area. In South Africa a large amount of citrus are lost because of the HLB disease in 1965 , from $30-100 \%$ in individual orchards. Some of these orchards at a later time had been abandoned or removed. Earlier explosion of the disease occurred in
1932-1936 and 1939-1946 ${ }^{[3]}$. In the Philippines reported crop yield of mandarin fell from 11,700 $t$ in 1960-100 $t$ in $1968^{[4]}$. In the Middle East, in south-western Saudi Arabia, sweet orange and mandarin pragmatically disappeared during the 1970s. Finally HLB has destroyed an estimated 60 million trees in Africa and Asia ${ }^{[5]}$. USA has been infected by HLB since $2005^{[6]}$.

However, HLB is transferred by two insect vectors-the asian psyllid Diaphorina citri and the african psyllid vector Trioza erytreae.Diaphorina citri. The latter was observed and detected in South, Central and North America (Florida and Texas) .There is little information on seed transmission and HLB pathogen movement. There are many questions about HLB seed transformation and movement. Is the greening bacterium seed borne? What are the implications? How long does it take the pathogens reach to root or leaf

Corresponding Author: Thohirah Lee Abdullah, Departments of Crop Science, Faculty of Agriculture, University Putra Malaysia, 43400 Serdang, Selangor Darul Ehsan Tel: +603-8946 6947 Fax: +603-8943 5973 
after inoculation? Does the pathogen reach the root? Citrus seedlings are produce on rootstocks which were propagated by seeds. If seed transmission occurs in cultivars that are used for citrus rootstocks, spread could occur through liners as well as by budding ${ }^{[7]}$. HLB's big problem of transmission was recorded in the early 80s. Tirtawidjaja collected insect samples on fruit from disease trees and all samples that were assayed for citrus greening were found to be negative ${ }^{[8]}$. Now, PCR can be used to determine the presence or absence of HLB on seeds. All these questions cannot be answered by just on one experiment. However this study was conducted to detect HLB pathogen causing greening disease in seeds of citrus, to determine pathogen movement in citrus seedling after infection and to detect the HLB pathogen in the roots of citrus.

\section{MATERIALS AND METHODS}

Two experiments were conducted to determine if HLB disease in citrus is seed borne and to verify the movement of HLB in citrus.

Experiment 1: Determination of the presence of HLB in seed of Citrus reticulate: Seeds were collected from HLB infected citrus plot in Terengganu and UPM. Positive identification of HLB in plant was determined using PCR test. Seeds were sown in insect-proof screenhouse (Fig 1A and B). The seeds germinated after two weeks and out of it 20 seedlings were maintained. Leaf samples were collected from the seedlings six months later for detection of HLB. Two weeks later another test was conducted by collecting leaf sample from new shoots. Seeds from none infected tree were also collected and planted for comparing between healthy and infected plants.

Leaf tissues of citrus seedlings were treated with liquid nitrogen and it was pounded using the mortar and pestle. Then the DND was extracted using the method of extraction developed by Hung in $1999^{[9]}$. Embryo of the seeds or leaf tissue of seedlings $(100 \geq \mathrm{mg})$ was cut into small pieces and ground in liquid nitrogen and transferred into 1.5 eppendorf tubes. Afterwards, $1.4 \mathrm{~mL}$ of DNA extraction buffer [1M Tris-HCL (pH 8.0), $0.5 \mathrm{M} \mathrm{NaCl}, 1 \% \mathrm{~N}$-Lauroylsarcosine] was added. The mixture was incubated at $55^{\circ} \mathrm{C}$ for $1 \mathrm{~h}$ and centrifuged at $6,000 \mathrm{~g}$ for $10 \mathrm{~min}$. The supernatant was collected and transferred into a new tube and added with $0.1 \mathrm{~mL}$ of $5 \mathrm{M} \mathrm{NaCl}$ and $10 \% \mathrm{CTAB}$ in $0.7 \mathrm{M}$ $\mathrm{NaCl}$. The mixture was incubated at $65^{\circ} \mathrm{C}$ for $15 \mathrm{~min}$, inverted 2-3 times during the incubation. DNA was extracted by an additional two cycles of chloroform/isoamyl alcohol (24:1) and (24:25:1). The aqueous supernatant was collected and added with 0.6 volume of isopropanol followed by centrifugation at $13,000 \mathrm{~g}$ for $15 \mathrm{~min}$. The pellets were washed with $70 \%$ ethanol, dried and resuspended in $30 \mu \mathrm{L}$ of sterile TE buffer ${ }^{[9]}$.

The PCR reaction was carried out in $25 \mu \mathrm{L}$ of reaction mixture containing $1 \mu \mathrm{M}$ of each primer, $0.2 \mathrm{~mm}$ of each four dNTPs, 1X PCR buffer mix, 0.5 units Taq DNA polymerase and $1 \mu \mathrm{L}$ DNA template. Specific primers, forward primer OI1 (5'-GCG CGT ATG CAA TAC GAG CGG CA-3') and reverse primer OI2c (5'-GCC TCG CGA CTT CGC AAC CCA T-3'), were used for amplification of the 16S rDNA of the Candidatus Liberibacter asiaticus ${ }^{[9]}$. The thermal cycle conditions were: one cycle at $94^{\circ} \mathrm{C}$ for $2 \mathrm{~min} ; 35$ cycles at $95^{\circ} \mathrm{C}$ for $40 \mathrm{sec} ; 60^{\circ} \mathrm{C}$ for $1 \mathrm{~min}$ and $72^{\circ} \mathrm{C}$ for 1 min; followed by $72^{\circ} \mathrm{C}$ extension for $10 \mathrm{~min}^{[9]}$.

The PCR products were analyzed by gel electrophoresis using a $1.2 \%$ agarose (Boehringer Mannheim, Mannheim, Germany) in TE buffer (Tris base, boric acid and 0.5 M EDTA [pH 8.0]) and stained with ethidium bromide $(0.5 \mathrm{uglml})$ and photographed. The 1000 bp DNA Ladder set (Promega, Madison, WI, USA) was included as size markers. The electrophoresis was run for 30-40 min using high voltage $(100 \mathrm{~V})$. The gel was visualized and analyzed by GEL documentation (SYNGENE; GENE Genious Bio Imaging System).

Experiment 2: Determination of HLB pathogen movement in Citrus reticulate: Seeds were sown and grown in the screenhouse until the seedlings were 40$50 \mathrm{~cm}$ tall. The infected scions of Citrus reticulate were grafted on the seedlings. A total of 24 seedlings were inoculated by wedge grafting at $30 \mathrm{~cm}$ above soil level. The seedlings were grafted and covered by plastic bag for 2 weeks.

First samplings were taken 4 weeks after inoculation; subsequent samplings were taken at 2 weeks interval. Each sampling location will be determined by the distance 'travelled' by the pathogen. If the pathogen is detected at the specified location, the following sample location will start from that point. For example, samples were taken at $1.5,3$ and $4.5 \mathrm{~cm}$ below the wedge. Subsequent samples were collected at a location free from HLB. Therefore at six weeks, samples were collected from another seedling at 3, 4.5 and $6 \mathrm{~cm}$ below the wedge. Ten more samples were collected every two weeks and the sampling location was determined by the absence or presence of HLB as tested by PCR. 


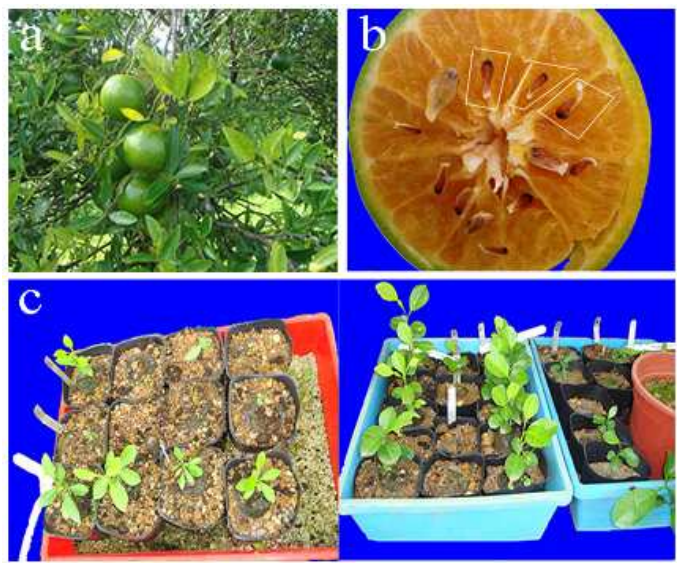

Fig. 1: (a): Infected fruits of Citrus reticulate on tree which has shown yellowing symptom of HLB; (b): Aborted seeds of Citrus reticulata shown in the fruit; (c): Seedling propagated from non aborted seeds of Citrus reticulata

A modified protocol was designed to extract DNA, as described by Hung in $1999^{[7]}$. DNA was extracted from HLB-infected tissue by Cetyl Trimethyl Ammonium Bromide (CTAB) method. The pellets were washed with $70 \%$ ethanol, dried and responded in $50 \mu \mathrm{L}$ TE buffer. This method was explained in the first experiment.

PCR was performed using $25 \mu \mathrm{L}$ of reaction mixture containing $1 \mu \mathrm{M}$ of each primer, $0.2 \mathrm{mM}$ of each four dNTPs, 1X PCR buffer mix, 0.5 units Taq DNA polymerase and $1 \mu \mathrm{L}$ DNA template. The PCR condition was explained in first experiment. The PCR reaction mixture were analyzed by electrophoresis on $1.2 \%$ agarose gel for about $30-45^{\prime}$ and visualized by ethidium bromide staining.

\section{RESULTS}

Experiment 1: Determination of seed born disease of HLB disease in citrus: Leaves of seedlings which were propagated from the infected trees were taken in order to assay HLB pathogen using conventional PCR after germination. It was amplified by the OI1 and OI2c primer sets. As shown in Fig. 2, HLB was not detected on the seedlings of Citrus reticulata. PCR amplification of seedlings which were propagated from the non infected source also showed the same result (Fig. 2A). After two weeks the test was conducted from the new flushes in the seedlings but the results were the same as the first test and HLB was not detected from the leaf samples (Fig. 2B).

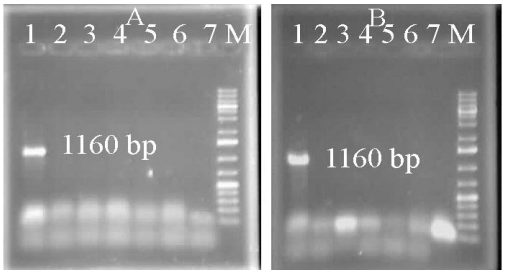

Fig. 2: (A): PCR amplification showing absence of HLB in seeds (line 1, positive control, line 2, 3, 4, 5, 6, leaf sample of Citrus reticulata on 5 reactions, line 7 leaf sample of the seedlings which were propagated from non infected source. line M, Marker). (B): PCR amplification conducted after two weeks still shows no signs of HLB in the seedlings (line1, positive control, line 2, 3, 4, 5, 6 leaf sample of Citrus reticulate on 5 reactions, line 7 leaf samples of the seedlings which were propagated from non infected source. line M, Marker)

Table 1: HLB pathogen detection on points below grafting area

\begin{tabular}{lll}
\hline $\begin{array}{l}\text { PCR test after } \\
\text { inoculation (weeks) }\end{array}$ & $\begin{array}{l}\text { Distance below } \\
\text { grafting area }(\mathrm{cm})\end{array}$ & PCR results \\
\hline 4 & 1.5 & + \\
6 & 3.0 & - \\
8 & 4.5 & + \\
10 & 6.0 & - \\
12 & 6.0 & - \\
14 & $6-9$ & + \\
16 & $10.5-15.0$ & + \\
18 & $16.5-21.0$ & - \\
20 & $16.5-24.0$ & + \\
22 & $25.5-28.5$ & + \\
24 & $28.5-30.0$ & + \\
26 & Root system & + \\
\hline
\end{tabular}

Experiment 2: Determination of HLB pathogen movement in susceptible citrus plant: There is little information on how long it would take before the pathogen can be detected on HLB infected citrus plants. Seeds of none infected Citrus reticulata were collected and germinated in screenhouse for this study. Based on this study, the pathogen moved from the infected scion to the rootstock after four weeks. The pathogen reached up to $1.5 \mathrm{~cm}$ below the grafting point after four weeks. It was also reached from $1.5-4.5 \mathrm{~cm}$ after eight weeks and detected on 4.5-9 cm after fourteen weeks (Fig. 3) below the grafting area (Table 1). Bové and Garnier ${ }^{[11]}$ observed foliar symptoms (blotchy mottle) of HLB on inoculated seedlings within 4 months and the HLB Liberibacter were detected by PCR in leaves ${ }^{[11]}$. HLB was detected in branches 2.5-3.5 months (10-14 weeks) after inoculation and symptoms were observed at the same time in shoots ${ }^{[7]}$. Results (Fig. 3) have shown that HLB was also detected up to $9-15 \mathrm{~cm}$ after 16 weeks, 
Am. J. Applied Sci., 6 (6): 1180-1185, 2009
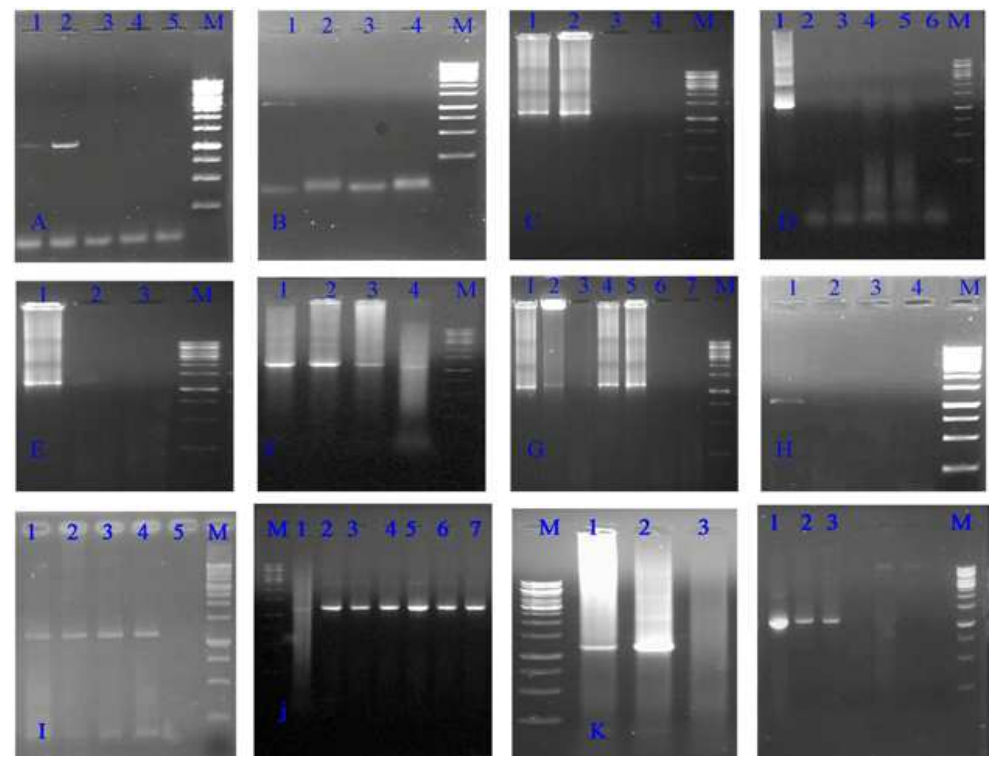

Fig. 3: 116s rDNA fragments with molecular weight of $1160 \mathrm{bp}$ were successfully amplified from infected points of bark of Citrus reticulate. (A): Four weeks after inoculation; (1-Positive control, 2-1.5 cm present of HLB on point below the grafting area, 3-4.5, 4-6 and 5-7.5 cm absence of HLB below the grafting area. M. Marker); (B): Six weeks after inoculation; (1-positive control. 2-3, 3-4.5 and 4-6 cm absence of HLB in points below the grafting area, M-Marker); (C): Eight weeks after inoculation; (1. positive control. 2-3 and 3-4.5 $\mathrm{cm}$ presence of HLB and 5-6 cm absence of HLB below the grafting area, M-Marker); (D): Ten weeks after inoculation; (1, positive control. 2-6, 3-7.5, 4-9, 5-10.5 and 6-12 cm absence of HLB in below the grafting area, M-Marker); (E): Twelve weeks after inoculation; (1-positive control, 2-6 and 3-7.5 absence of HLB in point below the grafting area, M-Marker); (F): Fourteen weeks after inoculation; (1-positive control, 2-6, 3-7.5 and 4-9 presence of HLB below the grafting area, M-Marker); (G): Sixteen weeks after inoculation; (1-positive control, 2-10.5, 312, 4-13.5 and 5-15 cm presence of HLB below the grafting area, 6-16.5 and 7-18 cm absence of HLB below the grafting area); $(\mathrm{H})$ : Eighteen weeks after inoculation; (1-positive control, 2-16.5, 3-18 and 4-19.5 cm absence of HLB in points below the grafting area, M-Marker); (I): Twenty weeks after inoculation;(1-positive control, 2-16.5, 3-18 and 4-19.5 cm presence of HLB below the grafting area, 5-21 cm absence of HLB in points below the grafting area, M-Marker); (j): Twenty two weeks after inoculation; (1-positive control, 2-21, 322.5, 4-24, 5-25.5, 6-27 and 7-28.5 cm presence of HLB below the grafting area, M-Marker); (K): Twenty four weeks after inoculation; (1-positive control, 2-30 cm presence of HLB in point's below the grafting area, 3negative control, M-Marker); (L): Twenty six weeks after inoculation; (1-positive control, 2-30 cm, 3-root system presence of HLB in point's below the grafting area M-marker)

$15-24 \mathrm{~cm}$ after twenty weeks, $24-28.5 \mathrm{~cm}$ after 22 weeks and $28.5-30 \mathrm{~cm}$ after twenty four weeks below the grafting area (Table 1).

\section{DISCUSSION}

According to the result on the first experiment, HLB was not detected on the seedlings after germination and is not seed borne. DNA probes now have been used successfully to detect Candidatus Liberibacter spp. both in infected plants and in psyllid vectors $^{[1,10]}$. There is little information about HLB disease seed transmission. Tirtawidjaja ${ }^{[8]}$ collected normal and greening-affected (very small) fruit and harvested 'normal-looking' seeds from each. No symptoms were observed on seedlings from seed taken from normal fruit. However, seeds derived from smaller, greening-affected fruit produced some stunted chlorotic seedlings ${ }^{[8]}$.

Citrus plants are usually produced using rootstocks and scion. If seed transmission occurs in cultivars like citrange that are used for citrus rootstocks, spread could occur through liners as well as by budding. In this case a healthy budding source is very important, because if the source used for propagation is infected with HLB, the disease will spread to the liners ${ }^{[7]}$. 
It was moved slowly due to the HLB situation and HLB pathogen is limited to the sieve tubes of the phloem tissue ${ }^{[12]}$. Phloem is a vascular tissue that transports sugar from the leaves to the rest of the plant. The vascular system is a transportation network of connected cells that form tunnels in the plant that extend from the roots through the stem to the leaves, flowers and fruits, but xylem transports water and minerals upwards from the roots and distributes it throughout the plant. Phloem transports the sugars created by photosynthesis from the leaves to other parts of the plant. These tunnels are bundled together and can be seen as the veins on a leaf ${ }^{[13]}$.

This movement or speed of HLB also depends on the susceptibility of species to HLB. Finally the destructive HLB pathogen was detected on root system 24 weeks after inoculation. Rootstocks become the root system for the scion and an interaction occurs between the scion and root system. HLB pathogen was detected in the root system of Luchen seedlings 5 months after graft inoculation $^{[7]}$.

Lopes et al. ${ }^{[14]}$ detected greening pathogen (Candidatus Liberobacter asiaticum) in young shoot samples pushed from remnants of the Citrus rootstock by PCR technology. He reported that the greening pathogen could survive in the root of the Citrus rootstock. He conducted his study on the effects of pruning to determine if removal of symptomatic branches or the entire canopy (decapitation) would eliminate infected tissues and save HLB affected trees. He reported mottled leaves reappeared on most symptomatic $(69.2 \%)$ as well on some asymptomatic $(7.6 \%)$ pruned trees, regardless of age, variety and pruning procedure. Presence of the pathogen (Candidatus Liberibacter americanus) in all symptomatic trees was confirmed by PCR. In general, the greater the symptom severity before pruning the lower the percentage of trees that remained asymptomatic after pruning ${ }^{[14]}$. Base on the results of this study HLB can reach the roots 26 weeks after inoculation. This means that resistant or tolerant rootstocks maybe effective to control or to reduce the severity of HLB, because rootstocks are provide the root system for the scion.

\section{REFERENCES}

1. Bové, J.M. et al., 1993. Detection of the Asian strains of the greening BLO by DNA-DNA hybridization in Indian orchard trees and malaysian diaphorina citri psyllids. Proceeding of the 12th Conference of the International Organization of Citrus Virologists, (CIOCv'93), Department of Plant Pathology, Riverside, California, University of California, pp: 258-263.
2. Garnier, M. and J.M. Bove, 1996. Distribution of the huanglongbing (greening) Liberobacter species in fifteen African and Asian countries. Proceeding of the 13th Conference of the International Organization of Citrus Virologists, (CIOCV'96), Department of Plant Pathology, University of California, Riverside, California, pp: 388-391.

3. Buitendag C.H. and A. von Broembsen, 1993. Living with citrus greening in South Africa. Proceedings of 12th Conference on International Organizational Citrus Virology, (CIOCV'93), Riverside, pp: 269-273.

4. Baniqued, C.A., 1998. Status of disease management of citrus in the Philippines. Managing banana and citrus disease. Proceeding of the Disease Management of Banana of Citrus through the Use of Disease-Free Planting Materials, Oct. 14-16, Davao City, Philippines, pp: 111-117.

http://www.cababstractsplus.org/abstracts/Abstract. aspx?AcNo=20026789583

5. Timmer, L.W. and S.M. Garnsey, 2003. Diseases of Citrus. In: Diseases of Tropical Fruit Crops, Ploetz, R.C. (Ed.). Tropical Research and Education Center, University of Florida, Homestead, Florida, USA., pp: 544. www.cabi.org/bk_BookDisplay.asp?SubjectArea= \&Subject

6. Texeira, D.C. et al., 2005 First report of a huanglongbing-like disease of citrus in sao paulo state, Brazil and association of a New Liberibacter Species, candidatus liberibacter americanus, with the disease. Plant Dis., 89: 107-107. www.bordeaux-aquitaine.inra.fr

7. Halbert, S.E. and K.L. Manjunath, 2004. Asian citrus psyllids (Sternorrhyncha: Psyllidae) and greening disease in citrus: A literature review and assessment of risk in Florida. Fla. Entomol., 87: 330-354. DOI: $10.1653 / 0015-$ 4040(2004)087[0330: ACPSPA] 2.0.CO; 2

8. Tirtawidjaja, S., 1981. Insect, dodder and seed transmissions of Citrus Vein Phloem Degeneration (CVPD). Proceeding of the 4th International Congress on Citrus, International Society of Citriculture, (ICCISc'81), Tokyo, Japon, pp: 469-471. http://www.crec.ifas.ufl.edu/societies/ISC/author/ja pan.htm

9. Hung, T.H., M.L. Wu and S.J. Hong, 1999. Development of rapid method for the diagnosis of citrus greening disease using polymerase chain reaction. Phytopathology, 147: 599-604. www.interscience.wiley.com/journal/119045384/a bstract?CRETRY=1\&SRETRY $=0$ 
10. Tian, Y., S. Ke and C. Ke, 1996. Polymerase chain reaction for detection and quantitation of Liberobacter asiaticum, the bacterium associated with huanglongbing (greening) of citrus in China. Proceeding of the 13th Conference on International Organization of Citrus Virologists, (IOCV'96), University of California, Riverside, California, pp: 252-257.

11. Bové, J. M. and M. Garnier, 1992. Citrus greening disease and its bacterial agent. Proceeding of the International Congress on Citrus, (ICC'92), International Society of Citriculture, Acireale, Italy, pp: 1283-1289.
12. Garnier, M., N. Danel and J.M. Bove, 1984. Aetiology of citrus greening disease. Ann. Microbiol. (Inst. Pasteur), 135A: 169-179. DOI: 10.1016/S0769-2609(84)80075-7

13. Richter, H.G. and M.J. Dallwitz, 2003. Supporting tissues vascular tissues, in last change. Botany online The Internet Hypertextbook International Edition. www.biologie.uni-hamburg.de/bnline/e00/contents.htm

14. Lopes, S., G. Frare, P. Yamamoto, A. Ayres and J. Barbosa, 2007. Ineffectiveness of pruning to control citrus huanglongbing caused by Candidatus Liberibacter americanus. Eur. J. Plant Pathol., 119 : 463-468. DOI: 10.1007/s10658-007-9173-1 